\title{
BMJ Open Foot health and quality of life in patients with rheumatoid arthritis: a cross-sectional study
}

\author{
Andres Reinoso-Cobo, ${ }^{1}$ Gabriel Gijon-Nogueron (D) ,, Rafael Caliz-Caliz, ${ }^{1}$ \\ Miguel Angel Ferrer-Gonzalez, ${ }^{1}$ Maria Teresa Vallejo-Velazquez, ${ }^{1}$ \\ Jose Miguel Morales-Asencio, ${ }^{2}$ Ana Belen Ortega-Avila ${ }^{3}$
}

To cite: Reinoso-Cobo A, Gijon-Nogueron G, CalizCaliz R, et al. Foot health and quality of life in patients with rheumatoid arthritis: a crosssectional study. BMJ Open 2020;10:e036903. doi:10.1136/ bmjopen-2020-036903

- Prepublication history for this paper is available online. To view these files, please visit the journal online (http://dx.doi. org/10.1136/bmjopen-2020036903).

Received 18 January 2020 Revised 16 April 2020 Accepted 17 April 2020

Check for updates

(C) Author(s) (or their employer(s)) 2020. Re-use permitted under CC BY-NC. No commercial re-use. See rights and permissions. Published by BMJ.

${ }^{1}$ Departamento de Reumatologia, Hospital Universitario Virgen de las Nieves, Granada, Spain

${ }^{2}$ Department Nursing and Podiatry, Universidad de Málaga, Instituto de Investigación Biomédica de Málaga (IBIMA), Malaga, Spain

${ }^{3}$ Department Nursing and Podiatry, Universidad de Málaga, Malaga, Spain

Correspondence to Dr Gabriel Gijon-Nogueron; gagijon@uma.es

\section{ABSTRACT}

Objective The aim of this study is to identify foot health factors related to the quality of life in patients with rheumatoid arthritis (RA).

Setting In this cross-sectional study, a total of 293 subjects were analysed, 229 of whom were in the RA group and 64 in the control group. In the RA group, 173 patients were female, and 50 in the control group. Participants Patients with foot pain and RA (according to the American College of Rheumatology/European League Against Rheumatism 2010 rheumatoid arthritis classification criteria) and with foot pain but no RA were recruited (Granada, Spain).

Intervention Two researchers independently interviewed the patients to obtain data for the study.

Primary and secondary outcome measures Clinical data were obtained using the Short Form 12-Item questionnaire (quality of life) (primary outcome), Visual Analogue Scale for pain (VAS pain), the Manchester Foot Pain Disability Index (MFPDI) and the Foot Function Index (FFI). Anthropometric measurements were obtained using a foot measurement platform, the Foot Posture Index and the Manchester Scale of Hallux Valgus (secondary outcomes). Results Of the 293 subjects, $76.1 \%$ were female. Significant differences were observed between the RA and the control group $(p<0.001)$ with regard to VAS pain (general, foot and hand), MFPDI and FFI. In terms of anthropometric measurements, significant differences were only recorded for midfoot and forefoot width $(p=0.03)$. For the physical health component, multivariable linear regression with the parameters age, gender, VAS pain (general) and the presence of RA presented an $R^{2}$ value of $48.8 \%$, while for the mental health component the corresponding value was $5.6 \%$.

Conclusion Morphological and structural characteristics of the foot are not necessarily associated with pain, disability and loss of function. The presence of RA, a higher score on VAS pain (general), female gender and older age are all associated with the physical component of the quality of life of patients with RA.

\section{INTRODUCTION}

Rheumatoid arthritis (RA) is a chronic rheumatic disease that affects $0.5 \%-1 \%$ of the population in Europe. ${ }^{1}$ The most characteristic symptom is swelling, which provokes
Strengths and limitations of this study

- Foot-related parameters are strongly associated with quality of life (QoL).

- Rheumatoid arthritis, higher score on the Visual Analogue Scale for pain, female gender and age are all related to the physical component of QoL.

- Neither Foot Posture Index nor any other anthropometric measurements are related to $\mathrm{QoL}$.

- QoL was analysed at a time when it might coincide with an aggravation of rheumatoid arthritis.

- A longitudinal study might provide different results.

important changes in joint structures and limits function. ${ }^{2}$

RA mainly affects the small joints of the hands and feet. ${ }^{3}$ In the foot, it provokes deformities in the forefoot and hindfoot. The most common pathologies are hallux valgus, metatarsal subluxation, and hammer or claw toes. ${ }^{4}$ As the disease progresses, the first metatarsophalangeal joint and pes planus may also be associated. These pathologies occur as the deterioration affects the joints and ligaments, ${ }^{5}$ thus limiting movement in the ankle and the foot. It also produces an unequal distribution of pressure, making it painful to remain in a standing position. ${ }^{6}$

$\mathrm{RA}$ is a systemic disease that not only presents extra-articular manifestations but also has psychological effects, ${ }^{7}$ in many cases provoking mental health and functional problems as a consequence of ageing, ${ }^{8}$ oxidative damage to DNA, and systemic inflammatory stress,${ }^{9}$ thus limiting leisure and family-related activities and restricting social relationships. ${ }^{10}$ The simultaneous impact of RA and reduced quality of life imposes a major burden on patients, caregivers, the health system and the society in general. ${ }^{11}$

The mental and physical components of RA can reduce adherence to treatment, leading 
to poorer health outcomes and a worsened quality of life. ${ }^{12}$

In patients with RA, the foot has been analysed from various standpoints, such as hallux valgus, clawed toes or morphological alterations. ${ }^{13}$ Psychological and social aspects of the disease have also been analysed, such as anxiety, depression and affectivity. ${ }^{14-16}$ However, to date no studies have been undertaken to determine whether RA in the foot has a negative impact on the quality of life, in terms of physical and mental health.

The aim of the present study, therefore, is to identify foot health factors related to the quality of life in patients with RA.

\section{METHODS \\ Design}

This is a cross-sectional study.

\section{Participants}

A convenience sample of 246 patients with foot pain and RA (according to the American College of Rheumatology/European League Against Rheumatism rheumatoid arthritis classification criteria) were obtained, ${ }^{17}$ of whom 17 subsequently declined to participate, citing lack of time (the study questionnaire required $30 \mathrm{~min}$ to complete), and 64 patients with foot pain but no RA. The patients were enrolled at hospital outpatient clinics from January to December 2018.

All those included in the study had a history of subtalar and/or ankle and/or talonavicular or hindfoot pain, with no daily use of walking aids, and were able to perform normal range of motions in the ankle, subtalar and midtarsal joints. Even if maximum dorsiflexion, pronation or supination in these joints could not be performed, a sufficient range of motion was achieved by adjusting the dynamics, for example by reducing stride length. ${ }^{6} 18$

The exclusion criteria applied were presence of concomitant musculoskeletal disease, central or peripheral nervous system disease, or endocrine disorders (especially diabetes mellitus).

Patients who met the inclusion criteria were approached by members of the rheumatology service at the Virgen de las Nieves Hospital (Granada, Spain), given an information sheet and invited to participate. Those who agreed to participate were then interviewed and given further details of the study. All participants provided written consent prior to starting the interviews.

\section{Data collection}

Demographic and clinical characteristics

The demographic characteristics recorded included the patient's age, gender, disease duration and current therapy. The clinical data recorded were those obtained from the Short Form 12-Item (SF-12) questionnaire, ${ }^{19}$ Visual Analogue Scale for pain (VAS pain), both general ${ }^{20}$ and specific to the foot and hand, the Manchester Foot
Pain Disability Index (MFPDI) ${ }^{21}$ and the Foot Function Index (FFI). ${ }^{22}$

For the anthropometric measurements, a foot measurement platform ${ }^{23}$ was used to measure foot length (weightbearing and non-weight-bearing), midfoot, forefoot and heel width, and midfoot height. Each participant was first asked to stand on the platform and then to be seated, in both cases with the body weight distributed evenly between the two feet, arms beside the body and facing forward. The measurements were obtained with the patient's heels placed in the heel cups, as far back as possible, and the first metatarsal heads located against the limit surface.

Other measurements were obtained using the Foot Posture Index (FPI), a reliable instrument designed for this purpose,${ }^{24}$ and the Manchester Scale of Hallux Valgus. ${ }^{25}$

\section{Procedures}

Two researchers (AR-C and GG-N) independently interviewed the patients to obtain data for the study. The clinical interview was conducted in one room, where the patients were asked to complete the SF-12 (adapted version for the Spanish population), ${ }^{26}$ MFPDI and VAS questionnaires. In a separate room, each patient was measured using a validated foot platform (intraclass correlation coefficient (ICC) for the instrument, 0.960.98). Foot posture was determined according to the FPI (ICC for the clinician, 0.94-0.96). Each criterion was scored as $-2,-1,0,+1$ or +2 . The following FPI cut-off points were used to define foot type category: (1) highly supinated, -12 to -4 ; (2) supinated, -3 to 0 ; (3) neutral, $1-7$; (4) pronated, 8-10; and (5) highly pronated, 11-12. ${ }^{27}$ The presence/absence of hallux valgus was determined according to the Manchester Scale of Hallux Valgus (ICC for the instrument, 0.93-0.97), a clinical tool consisting of photographs of feet with four levels of hallux valgus: none, mild, moderate and severe. ${ }^{25}$

\section{Patient and public involvement}

No patients were involved in setting the research question or the outcome measures, nor were they involved in the design or conduct of the study. No patients were asked to advise on interpretation or writing of the results. There are no plans to disseminate the results of the research to the study participants.

\section{Statistical analysis}

The results obtained are reported as median and IQR due to the non-normal distribution of the variables. Normality of the distribution was examined using the Kolmogorov-Smirnov test, and the intrarater reliability of the measurement instruments was calculated by a two-way mixed-consistency ICC model. Bivariate analysis was performed with a non-parametric test (the MannWhitney $U$ test), in view of the non-normal distribution observed in most cases. Finally, a multivariable linear regression model was obtained to evaluate the predictors 
of quality of life, according to the physical and mental health components of the SF-12 questionnaire. In constructing the models, the regression assumptions of homoscedasticity, normality and independence of the residuals and collinearity were tested. Homoscedasticity was evaluated by analysing the distribution of predicted values and scatterplots of the residuals. Normality of the residuals was tested by analysing histograms and by graphs of standardised residuals. Independence of the residuals was evaluated by the Durbin-Watson statistics. Finally, the presence of collinearity was tested by calculating the variance inflation factor, the tolerance and partial correlations. The significance level was set at $\mathrm{p}<0.05$, with two-tailed tests. All statistical analyses were conducted using SPSS V.24.0 statistical software and GPower V.3.1.92 for post-hoc analyses.

\section{RESULTS}

In total, 293 subjects were analysed, 229 of whom were in the RA group (average duration of RA 15.4 years, SD 10.5 years) and 64 in the control group. In the RA group, 173 patients were female, and 50 in the control group. The median age and IQR were 59 and 16 years for the patients with RA and 53 and 21 years for those in the control group. The median height and weight were $162 \mathrm{~cm}$ (IQR: 10) and $70 \mathrm{~kg}$ (IQR: 19), respectively, for the RA group, and $162 \mathrm{~cm}$ (IQR: 10) and $65 \mathrm{~kg}$ (IQR: 15), respectively, for the control group. The patients with RA were treated with biological disease-modifying antirheumatic drugs $(42 \%)$, methotrexate $(35 \%)$ or non-steroidal anti-inflammatory drugs/corticosteroids $(20 \%)$.

The instruments used to measure pain, disability and functionality (VAS pain, MFPDI and FFI) revealed significant differences between the patients with RA and the control group, for both genders $(p<0.001)$. However, among those used to obtain foot measurements and posture data, only the midfoot height values $(\mathrm{p}=0.007$ and $\mathrm{p}=0.004$ ) for male and female participants and midfoot width $(p=0.03)$ for female participants were statistically significant. The FPI and the other anthropometric measurements were not statistically significant (table 1).

The results from the SF-12 quality of life questionnaire revealed significant differences in the physical component between female $(\mathrm{p}<0.001)$ and male $(\mathrm{p}=0.02)$ participants, and in the mental component among female participants $(p=0.04)$ (table 2$)$. Among the male participants, no differences in the mental health component were observed between the RA and the control group.

Bivariate analyses were performed to determine the relations between the physical and mental health components, taking into account the sociodemographic, clinical and anthropometric characteristics of the participants. Among these results, especially noteworthy was the value of -0.630 with $\mathrm{p}<0.001$ obtained for VAS pain (general) and that of -0.505 with $\mathrm{p}<0.001$ for the presence of RA. Neither the anthropometric characteristics, foot posture nor disease duration presented any correlation with either of these variables.

Multivariate models were then constructed, using as predictors the variables that had presented a significant association in the bivariate models, adjusted for age and gender. Two models were calculated, with the physical and mental health components respectively as dependent variables.

According to the data for the physical component, the multivariable linear regression presented an $\mathrm{R}^{2}$ value of $48.8 \%$ (table 3). Post-hoc analysis yielded a power of 0.95 for this four-predictor model. The multivariable linear regression of the mental health component presented an $\mathrm{R}^{2}$ value of $5.6 \%$. There was no collinearity in the model (maximum variance inflation factor (VIF) 1.39 and minimum tolerance of 0.72 ) and the residuals were independent (Durbin-Watson, 1.19), using the same parameters (ie, age, gender, general VAS pain and the presence of RA).

\section{DISCUSSION}

The aim of this study is to determine and analyse foot health factors related to the quality of life of patients with RA. The multivariate regression results obtained suggest that patients with foot pain and RA perceive a significantly lower level of health than those with foot pain but no RA (control group) $(\mathrm{p}<0.001)$. However, these findings are not directly related to the clinical parameters that might have triggered the increased level of pain. The deformations which are typical of this disease and which are located in the forefoot (such as hallux valgus, hallux rigidus, floating of the lesser toes or synovial inflammation of the metatarsophalangeal joints) or in the hindfoot (such as hindfoot valgus or flat foot) are often believed to aggravate pain and disability among this population. Nevertheless, this expectation was not borne out by our study results, possibly because the presence of RA in itself is painful, while other patients with similar foot deformities but no RA might not experience pain. If this were the case, then the deformity would not be the cause of pain, but merely the outcome of a degenerative process in the foot. However, analysis of plantar pressures shows that this localised pain is not correlated with peak plantar pressure, which is received in the hindfoot.

Structural alterations in the foot not only cause physical deterioration due to reduced mobility, but can also lead to emotional deterioration. Nevertheless, according to our study findings, these alterations are not in themselves the cause of increased pain. Instead, this outcome may be influenced by an external component, such as the choice of footwear, a factor that is strongly influenced by the appearance of structural alterations in the foot. We conclude, therefore, that patients should prioritise factors such as fit and comfort when choosing footwear. ${ }^{28}$

Many patients, especially women, have considerable difficulty in obtaining appropriate footwear, that is, one that is comfortable, designed according to the deformities 


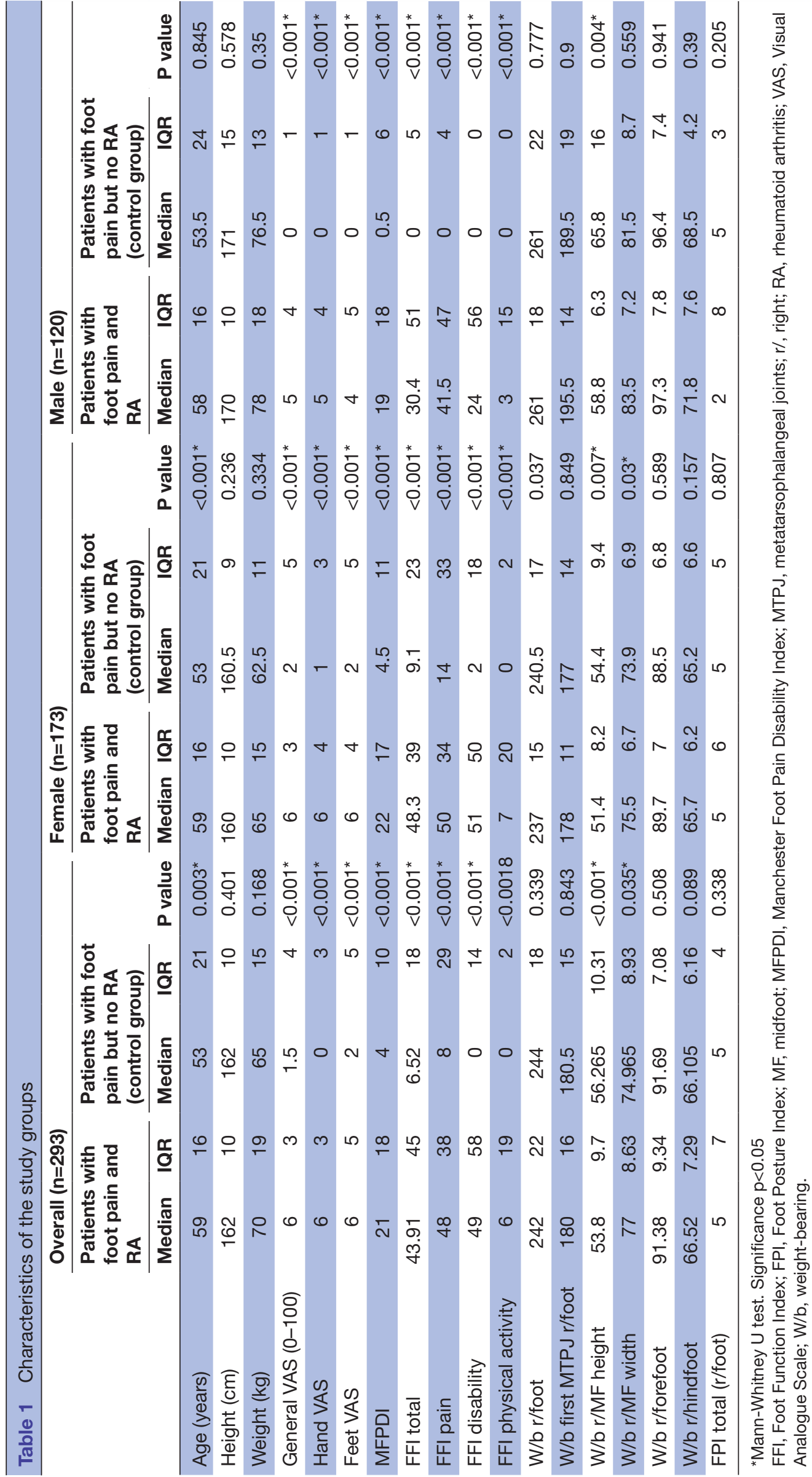


Table 2 Characteristics of the sample group according to the SF-12 results

\begin{tabular}{|c|c|c|c|c|c|c|c|c|c|c|}
\hline & \multicolumn{5}{|c|}{ Female } & \multicolumn{5}{|l|}{ Male } \\
\hline & \multicolumn{2}{|c|}{$R A(n=173)$} & \multicolumn{2}{|c|}{ Control group $(n=50)$} & \multirow[b]{2}{*}{ P value* } & \multicolumn{2}{|c|}{ RA (n=56) } & \multicolumn{2}{|c|}{ Control group $(n=14)$} & \multirow[b]{2}{*}{ P value } \\
\hline & Mean & SD & Mean & SD & & Mean & SD & Mean & SD & \\
\hline $\begin{array}{l}\text { Mental health } \\
\text { component (Ref. } \\
\text { Spanish population) }\end{array}$ & 32.10 & 7.97 & 35.08 & 5.00 & 0.04 & 33.76 & 1.65 & 36.14 & 4.66 & 0.35 \\
\hline
\end{tabular}

*Mann-Whitney $U$ test.

RA, rheumatoid arthritis; Ref, reference; SF-12, Short Form 12-Item questionnaire.

of the foot, assists in performing the gait cycle and is aesthetically acceptable. ${ }^{29} 30$

The latter characteristic is the area in which most negative impressions are caused among the population with RA, since many patients do not choose their footwear in strict accordance with the deformities of their feet. ${ }^{31}$ This discordance can have a negative impact on the patient, either in terms of the mental component (the perceived quality of life), when the personal image is compared with that of the non-affected population, or due to increased plantar pain, when the footwear chosen is uncomfortable and prevents proper mobilisation of the musculoskeletal structures of the foot, thereby limiting the performance of the activities of daily life. These outcomes are often associated with dissatisfaction and even depression among the population affected.

With advancing age, musculoskeletal deformities, and in particular structural alterations, in the foot increase, as a greater number of structures are damaged. These alterations may also be caused by increased neuropathy in the foot, which in turn would heighten pain and reduce functionality, ${ }^{1}$ thus worsening the perceived quality of life (impacting on anxiety and depression status in particular). ${ }^{32} 33$

This research presents certain limitations. First, it is based on a cross-sectional study of a heterogeneous sample population, rather than on a longitudinal study. This characteristic of study design may have influenced the results obtained in two respects. On the one hand, in our sample the number of participants with RA significantly exceeded those not presenting this alteration.
Therefore, if the size of the control group were increased, somewhat different results might be obtained. Moreover, as the analysis was transversal, both the physical and mental components were analysed at a time when they might have coincided with an aggravation of RA, thus altering the results obtained.

Another limitation of our study is that it is based on a convenience sample, which means that the homogeneity of the participants cannot be assured. In future research, therefore, the size and composition of the study groups should be controlled to optimise their homogeneity. Finally, attention should be paid to the question of whether foot pain is determined by the characteristics of the foot, or whether RA pain affects certain foot types in particular.

Our study shows that patients with RA are more likely to present structural alterations in the foot and hence to experience physical and/or psychosocial deterioration than when this condition is absent. ${ }^{34}$ Furthermore, the long-term evolution of the disease may be directly related to psychosocial and emotional perceptions. It should also be taken into account that in our study groups most of the patients were female, although this reflects their prevalence among the general population affected by RA and foot pain. ${ }^{3536}$ Psychosocial status was also increased in this female population due to factors such as being in employment or the presence of positive body image perceptions. $^{37-39}$

On the other hand, the study also has important strengths. Although the results obtained do not show that foot-related parameters are strongly associated with

Table 3 Model of multivariate regression for the perception of physical health

\begin{tabular}{|c|c|c|c|c|c|c|}
\hline & \multirow[b]{2}{*}{ Adjusted coefficient } & \multirow[b]{2}{*}{ B } & \multirow[b]{2}{*}{$\boldsymbol{\beta}$} & \multirow[b]{2}{*}{$P$ value } & \multicolumn{2}{|l|}{$95 \% \mathrm{Cl}$} \\
\hline & & & & & Lower & Upper \\
\hline Age & -0.175 & -0.082 & -0.113 & 0.038 & -0.159 & -0.005 \\
\hline VAS pain: general & -2.177 & -1.609 & -0.474 & $<0.001$ & -2.024 & -1.193 \\
\hline RA & -11.769 & -6.461 & -0.292 & $<0.001$ & -9.111 & -3.811 \\
\hline
\end{tabular}

RA, rheumatoid arthritis; VAS, Visual Analogue Scale. 
the quality of life of these patients, they do highlight the need for further, longitudinal studies addressing parameters such as the evolution of the disease, the treatment received and the psychosocial aspects that could influence the patient's perception of the impact of RA with respect to daily activities and musculoskeletal pain.

In the clinical context, our study raises an important question, namely that the pain and the reduced quality of life experienced by patients with RA may be provoked by the disease itself, and not by the alterations in the foot. If this were so, the presence of the latter might not be related to the pain experienced.

\section{CONCLUSIONS}

Morphological and structural characteristics of the foot are not necessarily associated with pain, disability and loss of function. The presence of RA, higher score on general VAS pain, female gender and older age are all related to reduced quality of life in the physical component of patients with RA.

Contributors Conceptualisation: GG-N, RC-C, JMM-A and ABO-A. Data curation: AR-C. Formal analysis: GG-N, JMM-A and ABO-A. Methodology: GG-N, RC-C, MAF-G and ABO-A. Project administration: MTV-V. Writing of original draft: AR-C, GG-N and ABO-A. Review and editing: AR-C, GG-N, RC-C, JMM-A and ABO-A.

Funding The authors have not declared a specific grant for this research from any funding agency in the public, commercial or not-for-profit sectors.

Competing interests None declared.

Patient consent for publication Obtained.

Ethics approval The study was approved by the Medical Research Ethics Committee of the University of Malaga (CEUMA-91-2015H) and PEIBA Andalucia (ARC0001), Spain

Provenance and peer review Not commissioned; externally peer reviewed.

Data availability statement № data are available.

Open access This is an open access article distributed in accordance with the Creative Commons Attribution Non Commercial (CC BY-NC 4.0) license, which permits others to distribute, remix, adapt, build upon this work non-commercially, and license their derivative works on different terms, provided the original work is properly cited, appropriate credit is given, any changes made indicated, and the use is non-commercial. See: http://creativecommons.org/licenses/by-nc/4.0/.

ORCID iD

Gabriel Gijon-Nogueron http://orcid.org/0000-0003-4558-3548

\section{REFERENCES}

1 de Andrade AP, Inoue EN, Nisihara R, et al. Foot function in rheumatoid arthritis patients: a cross-sectional study. Clin Rheumatol 2018;37:3427-30.

2 Gabriel SE, Michaud K. Epidemiological studies in incidence, prevalence, mortality, and comorbidity of the rheumatic diseases. Arthritis Res Ther 2009;11:229.

3 Stolt M, Suhonen R, Leino-Kilpi H. Foot health in patients with rheumatoid arthritis-a scoping review. Rheumatol Int 2017;37:1413-22.

4 Siddle HJ, Hodgson RJ, Hensor EMA, et al. Plantar plate pathology is associated with erosive disease in the painful forefoot of patients with rheumatoid arthritis. BMC Musculoskelet Disord 2017;18:1-9.

5 Jaakkola JI, Mann RA. A review of rheumatoid arthritis affecting the foot and ankle. Foot Ankle Int 2004;25:866-74.

6 Otter SJ, Lucas K, Springett K, et al. Foot pain in rheumatoid arthritis prevalence, risk factors and management: an epidemiological study. Clin Rheumatol 2010;29:255-71.
7 Margaretten M, Julian L, Katz P, et al. Depression in patients with rheumatoid arthritis: description, causes and mechanisms. Int $J$ Clin Rheumtol 2011;6:617-23.

8 Lu M-C, Guo H-R, Lin M-C, et al. Bidirectional associations between rheumatoid arthritis and depression: a nationwide longitudinal study. Sci Rep 2016;6:20647.

9 Malemud CJ, Miller AH. Pro-Inflammatory cytokine-induced SAPK MAPK and JAK/STAT in rheumatoid arthritis and the new antidepression drugs. Expert Opin Ther Targets 2008;12:171-83.

10 Matcham F, Rayner L, Steer S, et al. The prevalence of depression in rheumatoid arthritis: a systematic review and meta-analysis. Rheumatology 2013;52:2136-48.

11 Sambamoorthi U, Shah D, Zhao X. Healthcare burden of depression in adults with arthritis. Expert Rev Pharmacoecon Outcomes Res 2017:17:53-65

12 DiMatteo MR, Lepper HS, Croghan TW. Depression is a risk factor for noncompliance with medical treatment: meta-analysis of the effects of anxiety and depression on patient adherence. Arch Intern Med 2000;160:2101-7.

13 Hafström I, Engvall I-L, Rönnelid J, et al. Rheumatoid factor and antiCCP do not predict progressive joint damage in patients with early rheumatoid arthritis treated with prednisolone: a randomised study. BMJ Open 2014;4:e005246.

14 Vamos M, White GL, Caughey DE. Body image in rheumatoid arthritis: the relevance of hand appearance to desire for surgery. $\mathrm{Br} \mathrm{J}$ Med Psychol 1990;63:401.

15 Williams AE, Graham AS. 'My feet: visible, but ignored...' A qualitative study of foot care for people with rheumatoid arthritis. Clin Rehabil 2012;26:952-9.

16 Rathbun AM, Reed GW, Harrold LR. The temporal relationship between depression and rheumatoid arthritis disease activity, treatment persistence and response: a systematic review. Rheumatology 2013;52:1785-94.

17 Aletaha D, Neogi T, Silman AJ, et al. 2010 rheumatoid arthritis classification criteria: an American College of Rheumatology/ European League against rheumatism collaborative initiative. Ann Rheum Dis 2010;69:1580-8.

18 Dubbeldam R, Baan $\mathrm{H}$, Nene AV, et al. Foot and ankle kinematics in rheumatoid arthritis: influence of foot and ankle joint and leg tendon pathologies. Arthritis Care Res 2013;65:503-11.

19 Luo X, George ML, Kakouras I, et al. Reliability, validity, and responsiveness of the short form 12-Item survey (SF-12) in patients with back pain. Spine 2003;28:1739-45.

20 Sendlbeck M, Araujo EG, Schett G, et al. Psychometric properties of three single-item pain scales in patients with rheumatoid arthritis seen during routine clinical care: a comparative perspective on construct validity, reproducibility and internal responsiveness. $R M D$ Open 2015;1:e000140.

21 Gijon-Nogueron G, Ndosi M, Luque-Suarez A, et al. Cross-Cultural adaptation and validation of the Manchester foot pain and disability index into Spanish. Qual Life Res 2014;23:571-9.

22 Paez-Moguer J, Budiman-Mak E, Cuesta-Vargas Al. Cross-Cultural adaptation and validation of the foot function index to Spanish. Foot Ankle Surg 2014;20:34-9.

23 McPoil TG, Vicenzino B, Cornwall MW, et al. Can foot anthropometric measurements predict dynamic plantar surface contact area? J Foot Ankle Res 2009;2:1-9.

24 Redmond AC, Crosbie J, Ouvrier RA. Development and validation of a novel rating system for scoring standing foot posture: the foot posture index. Clin Biomech 2006;21:89-98.

25 Garrow AP, Papageorgiou A, Silman AJ, et al. The grading of hallux valgus. The Manchester scale. J Am Podiatr Med Assoc 2001;91:74-8.

26 Schmidt S, Vilagut G, Garin O, et al. Normas de referencia para El Cuestionario de Salud SF-12 versión 2 basadas en población General de Cataluña. Med Clin 2012;139:613-25.

27 Redmond AC, Crane YZ, Menz HB. Normative values for the foot posture index. J Foot Ankle Res 2008;1:6.

28 Tovaruela-Carrión N, Becerro-de-Bengoa-Vallejo R, Losa-Iglesias $\mathrm{ME}$, et al. Accurately determining proper shoe size in patients with rheumatoid arthritis. Rehabil Nurs 2018;43:285-9.

29 Naidoo S, Anderson S, Mills J, et al. "I could cry, the amount of shoes I can't get into": A qualitative exploration of the factors that influence retail footwear selection in women with rheumatoid arthritis. $J$ Foot Ankle Res 2011;4:21.

30 Goodacre LJ, Candy FJ. 'If I didn't have RA I wouldn't give them house room': the relationship between RA, footwear and clothing choices. Rheumatology 2011;50:513-7.

31 Reina-Bueno M, Vázquez-Bautista MDC, Pérez-García S, et al. Effectiveness of custom-made foot orthoses in patients with rheumatoid arthritis: a randomized controlled trial. Clin Rehabil 2019;33:661-9. 
32 Perry MG, Richards L, Harbuz MS, et al. Sequential synovial fluid sampling suggests plasma and synovial fluid IL-6 vary independently in rheumatoid arthritis. Rheumatology 2006;45:229-30.

33 Li Y, Jiang L, Zhang Z, et al. Clinical characteristics of rheumatoid arthritis patients with peripheral neuropathy and potential related risk factors. Clin Rheumatol 2019;38:2099-107.

34 Gates LS, Arden NK, Hannan MT, et al. Prevalence of foot pain across an international Consortium of Population-Based cohorts. Arthritis Care Res 2019;71:661-70.

35 Sokka T, Toloza S, Cutolo M, et al. Women, men, and rheumatoid arthritis: analyses of disease activity, disease characteristics, and treatments in the QUEST-RA study. Arthritis Res Ther 2009;11:R7.
36 Kvien TK, Uhlig T, Ødegård S, et al. Epidemiological aspects of rheumatoid arthritis: the sex ratio. Ann N Y Acad Sci 2006;1069:212-22.

37 Kobelt G, Texier-Richard B, Mimoun S, et al. Rheumatoid arthritis and sexuality: a patient survey in France. BMC Musculoskelet Disord 2012;13:170.

38 Lacaille D, White MA, Backman CL, et al. Problems faced at work due to inflammatory arthritis: new insights gained from understanding patients' perspective. Arthritis Rheum 2007;57:1269-79.

39 López-López D, Becerro-de-Bengoa-Vallejo R, Losa-Iglesias ME, et al. Evaluation of foot health related quality of life in individuals with foot problems by gender: a cross-sectional comparative analysis study. BMJ Open 2018;8:e023980. 